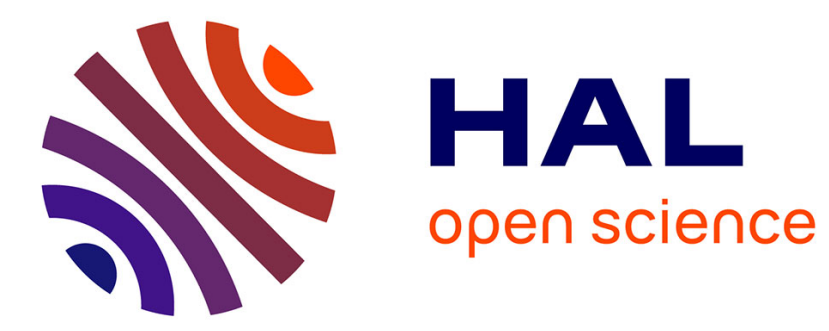

\title{
Stereochemically enriched extractants for the extraction of actinides
}

\author{
Guilhem Arrachart, N. Felines, Fabrice Giusti, A. Beillard, C. Marie, S \\ Pellet-Rostaing
}

\section{- To cite this version:}

Guilhem Arrachart, N. Felines, Fabrice Giusti, A. Beillard, C. Marie, et al.. Stereochemically enriched extractants for the extraction of actinides. New Journal of Chemistry, 2021, 45 (29), pp.12798-12801. 10.1039/d1nj02077c . hal-03395204

\section{HAL Id: hal-03395204 \\ https://hal.science/hal-03395204}

Submitted on 25 Oct 2021

HAL is a multi-disciplinary open access archive for the deposit and dissemination of scientific research documents, whether they are published or not. The documents may come from teaching and research institutions in France or abroad, or from public or private research centers.
L'archive ouverte pluridisciplinaire HAL, est destinée au dépôt et à la diffusion de documents scientifiques de niveau recherche, publiés ou non, émanant des établissements d'enseignement et de recherche français ou étrangers, des laboratoires publics ou privés. 


\title{
Stereochemically enriched extractants for the extraction of actinides
}

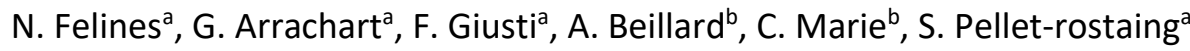 \\ a ICSM, Univ. Montpellier, CEA, CNRS, ENSCM, Marcoule, France. E-mail: guilhem.arrachart@umontpellier.fr \\ ${ }^{b}$ CEA, DES, ISEC, DMRC, Univ. Montpellier, Marcoule, France
}

\begin{abstract}
Numerous studies on the understanding of extraction mechanisms and complex structures have been done for hydrometallurgical processes. However, investigations on the influence of extractants stereochemistry on extraction performances has not been fully understood or even studied at all. In the present study, promising results for the extraction of actinides have been obtained using different stereoisomers of the extractant di-2-ethylhexylbutyramide (DEHBA) which highlights the importance of the extractant chirality.
\end{abstract}

Extraction and recycling of metals are nowadays one of the main challenge of the industry. Every year, a large number of new extractant molecules are designed and synthesised. The chemical structure of these extractants has an influence on the affinity toward metals and aggregation properties. It has been shown that the change of the chemical structure - in particular by using alkyl groups with different branching - plays an important role in the extraction behaviours. ${ }^{1,2,3,4}$ For example, main powerful extractants used in hydrometallurgy such as HDEHP, Cyanex 272, Cyanex 301 or lonquest 801 display branched alkyl chains. It has been noticed that the same molecular pattern is present on many of these extractant molecules. The di-2-ethylhexyl group is largely introduced on the structure of these molecules to provide hydrophobic properties as well as specific steric effects on metal affinity. This alkyl chain is branched with an ethyl group on second position and therefore an asymmetric carbon on its skeleton, providing chirality to the molecule.

Through some studies, it appears that the stereocontrolled substitutions on ligands may provide new and interesting possibilities in the development of specific extraction processes. Among them, Lemaire et al. have highlighted the role of optical purity in metal extraction and separation through the use of pure stereoisomers of crown ether compounds for the extraction of various metals including plutonium, showing a difference between the cis-syn-cis and cis-anti-cis molecules with an extraction factor comprised between two and four time higher. ${ }^{5}$ The effectiveness of the stereoisomers was studied for the design of synergistic metal ion extraction systems. ${ }^{6}$ These stereoisomers were also studied towards zinc isotope separation with a better fractionation obtained with the cis-syncis derivative. ${ }^{7}$
Tsukube et al. have shown different behaviour using a stereocontrolled ter-pyridine molecule for the extraction of silver element. ${ }^{8}$ Also, liquid-liquid extraction experiments using chiral tris(2-pyridylmethyl)amine ligands have shown differences in metal extraction for different diastereomers. ${ }^{9}$ Recently, significant differences in the extraction efficiency and selectivity of trivalent $f$ elements have been highlighted for two diastereomers of dimethyl tetraoctyl diglycolamide (Me2TODGA). ${ }^{10}$

However, from such examples, it appears that the extraction efficiency of individual diastereomeric ligands which incorporate an asymmetric carbon on its alkyl chains such as di2-ethylhexyl groups have not been studied. Therefore, the present study is dedicated to the evaluation of chirality effect of di-2-ethylhexylbutyramide (DEHBA) on uranium and plutonium extraction. Even if $\mathrm{N}, \mathrm{N}$-dialkyl amides are much less described in the literature than malonamide and diglycolamide ligands ${ }^{11}$, these extractants have been proposed for the coextraction of uranium (U) and plutonium (Pu) from spent nuclear fuels due to their singular properties. ${ }^{12,13,14} \mathrm{~N}, \mathrm{~N}$-dialkyl amides exhibit strong capability to extract uranium(VI) and plutonium(IV) at high nitric acid concentration while their separation can be achieved by decreasing nitric acid concentration. The extraction properties of $\mathrm{N}, \mathrm{N}$-dialkyl amides depend on their structure ${ }^{3}$ but the stereochemistry has not been studied. With the aim to determine the influence of the stereochemistry, the synthesis of stereochemically pure isomers of DEHBA was investigated in order to compare their $\mathrm{U} / \mathrm{Pu}$ extraction efficiencies with the stereoisomeric (racemic) mixture. This molecule contains two chiral centers, one on each alkyl chain. This means that it possesses three different stereoisomers, two enantiomers and one meso isomer, which are shown in Figure 1. 


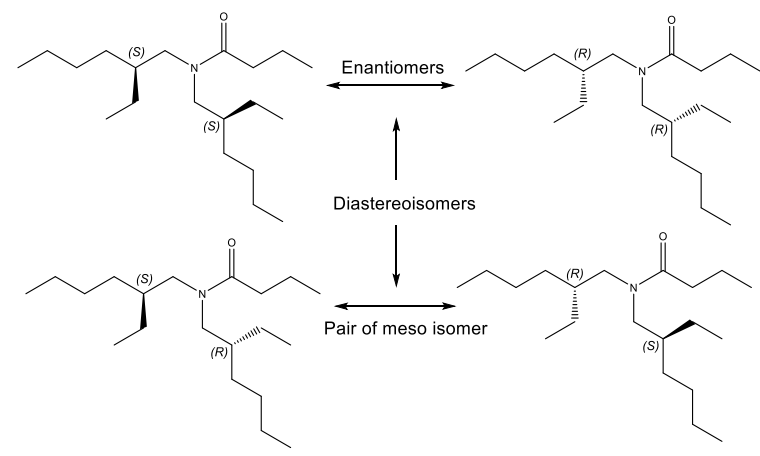

Figure 1 : Structure of the different stereoisomers of the molecule of di-2ethylhexylbutyramide (DEHBA).

Hence, the main target of this work was the synthesis of the stereochemically pure $(S, S)$ - and $(R, S)$-di(2-ethylhexyl)amine (Figure 2).

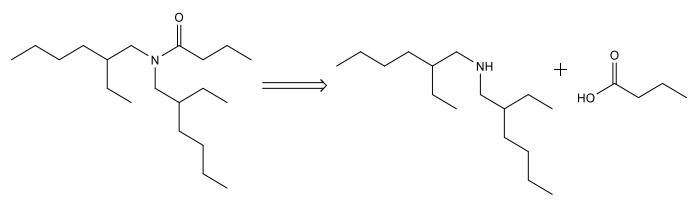

Figure 2: Retrosynthesis step suggestion for DEHBA

The optimal synthetic pathway for the di-2-ethylhexylamine was found through a search on the possible disconnection strategies, which involved an $\mathrm{N}$-alkylation reaction between the 3-(bromoethyl)heptane and 2-ethylhexylamine. Such building blocks can be obtained from the corresponding alcohol, namely the 2-ethylhexanol.

A strategy to obtain this enantiomerically enriched alcohol is described in details by Zerdan et al. ${ }^{15}$ applying Evans chiral auxiliary chemistry. ${ }^{16}$ This approach has been slightly modified and as function of the starting 4-benzyl-2-oxazolidinone used, $(R)$ or $(S)$-2-ethylhexanol can be obtained with a maximum global yield around $50 \%$ (Scheme 1 ).
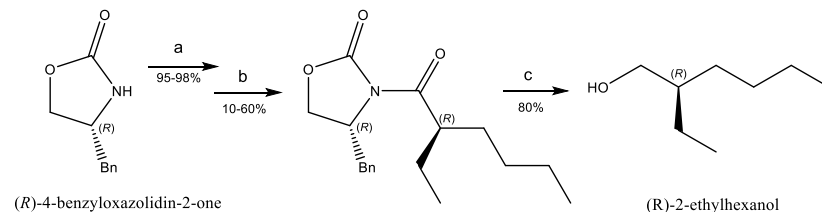

Scheme 1: Synthesis of enantiomerically enriched (R)-2-ethylhexanol from Evans' chiral oxazolidinone. Reaction conditions: (a) $n$-BuLi, $n$ - Hexanoyl chloride, THF, 95 $98 \%$ yield; (b) i. NaHMDS, THF, $-78{ }^{\circ} \mathrm{C}, 1 \mathrm{~h}$; ii. Etl, $-40{ }^{\circ} \mathrm{C}, 16 \mathrm{~h}, 10-60 \%$ yield; (c) $\mathrm{LiBH}_{4}, \mathrm{EtOH}, \mathrm{Et}_{2} \mathrm{O}, 0^{\circ} \mathrm{C}, 3 \mathrm{~h}, 80 \%$ yield.

Another opportunity to obtain enantiomerically enriched (S)-2-ethylhexanol has been proposed by Larpent et al., involving asymmetric recrystallization starting from racemic ethyl-2-hexanoic acid. ${ }^{17}$ This methodology (based on the separation of diastereoisomeric ammonium salts) allowed preparation of both $(R)$ and $(S)$-2-ethylhexanol starting respectively from (S)-methylbenzylamine or $(R)$ methylbenzylamine (Scheme 2).

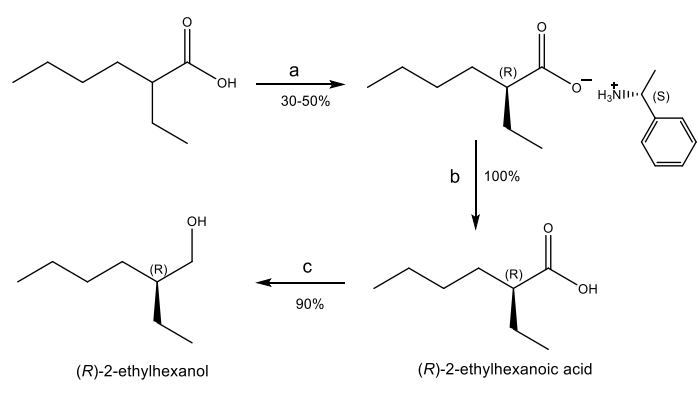

Scheme 2 : Synthesis of enantiomerically enriched (R)-2-ethylhexanol from selective crystallisation. Reaction conditions: (a) (S)-methylbenzylamine, $\mathrm{CH}_{3} \mathrm{CN}, 30-50 \%$ yield; (b) $\mathrm{HCl} 1 \mathrm{~mol} \mathrm{L-1}, \mathrm{Et}_{2} \mathrm{O}, 24 \mathrm{~h}, 100 \%$ yield; (c) $\mathrm{BH}_{3}-$ $\mathrm{SMe}_{2}, \mathrm{THF}, 90 \%$ yield.

Regardless of the approach considered, comparable yields were obtained with enantiomeric excesses determined by GCMS greater than $90 \%$, thus confirming the synthesis of enantiomerically enriched $(R)$-2-ethylhexanol or (S)-2-ethylhexanol.

Initially, access to the bromo and amino compound was considered by passing through a mesylate group (Scheme 3) instead of a tosylate group, as proposed by Zerdan et al. ${ }^{15}$. The amine is obtained from the reduction of the azide intermediate functional group.

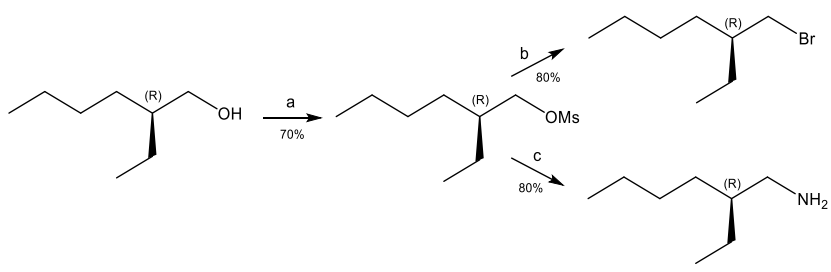

Scheme 3: Synthesis of enantiomerically enriched (R)-3-(bromoethyl) heptane and ( $R$ )2-ethylhexylamine from mesylate derivative. Reaction conditions: (a) $\mathrm{MsCl}, \mathrm{DMAP}, \mathrm{Py}$, $\mathrm{DCM}, 4^{\circ} \mathrm{C}, 48 \mathrm{~h}, 70 \%$ yield; (b) $\mathrm{LiBr}$, Acetone, Reflux $80^{\circ} \mathrm{C}, 16 \mathrm{~h}, 80 \%$ yield; (c) i. $\mathrm{NaN}_{3}$,

$\mathrm{CH}_{3} \mathrm{CN}, 120^{\circ} \mathrm{C}$ under $\mathrm{MW}, 18 \mathrm{~h}, 90 \%$ yield; ii. $\mathrm{LiAlH}_{4}, \mathrm{Et}_{2} \mathrm{O}, 0{ }^{\circ} \mathrm{C}, 3 \mathrm{~h}, 90 \%$ yield.

In order to reduce the number of reaction steps, a new synthetic route has been studied directly from the alcohol (Scheme 4). In the case of the brominated derivative, an Appel reaction was implemented ${ }^{18}$ from the reaction of triphenylphosphine and carbon tetrabromide with the corresponding alcohol. In the same way a Mitsunobu-type reaction was set up from diisopropylazodicarboxylate (DIAD), triphenylphosphine $\left(\mathrm{PPh}_{3}\right)$, and diphenylphosphorylazide (DPPA), allowing direct azidation of the alcohol molecule which after reduction leads to the amine.

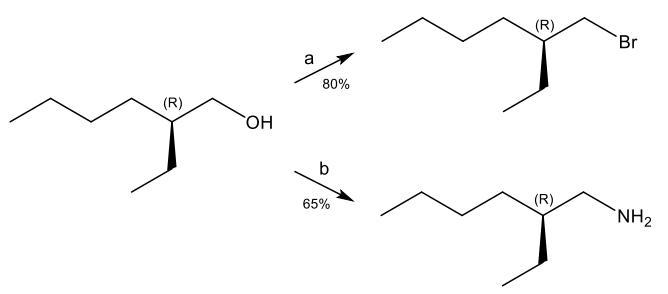

Scheme 4: Synthesis of enantiomerically enriched (R)-3-(bromoethyl) heptane and ( $R$ )2-ethylhexylamine from alcohol derivative. Reaction conditions: (a) $\mathrm{PPh}_{3}, \mathrm{CBr}_{4}, \mathrm{CH}_{2} \mathrm{Cl}_{2}$, $80 \%$ yield; (b) i. DIAD, $\mathrm{PPh}_{3}$, DPPA, THF, $70 \%$ yield; ii. $\mathrm{LiAlH}_{4}, \mathrm{Et}_{2} \mathrm{O}, 0{ }^{\circ} \mathrm{C}, 3 \mathrm{~h}, 90 \%$ yield. 
The targeted optically enriched di-2-ethylhexylamines were obtained by $\mathrm{N}$-alkylation reaction involving the bromo and amino compound. Finally, the DEHBA is obtained by an amide coupling via the "Schotten-Baumann reaction" with the acylation of the di-2-ethylhexylamine by butyryl chloride (Scheme 5). Finally, both stereochemically enriched isomers $(S, S)$-DEHBA, $(R, S)$-DEHBA were obtained with an enantiomeric excess greater than $90 \%$ and the stereoisomeric mixture of DEHBA was also isolated.

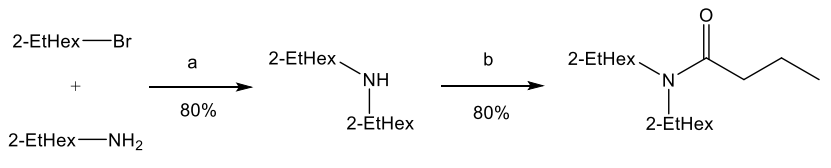

Scheme 5: Synthesis of DEHBA. Reaction conditions: (a) $\mathrm{K}_{2} \mathrm{CO}_{3}, \mathrm{CH}_{3} \mathrm{CN}, 120^{\circ} \mathrm{C}$ under $\mathrm{MW} 80 \%$ yield; (b) butyryl chloride, $\mathrm{K}_{2} \mathrm{CO}_{3}, \mathrm{CH}_{2} \mathrm{Cl}_{2}, 80 \%$ yield.

Extraction behaviour of $\mathrm{U}(\mathrm{VI})$ and $\mathrm{Pu}(\mathrm{IV})$ has been studied employing $1.2 \mathrm{~mol} \mathrm{~L}^{-1}$ DEHBA (stereoisomeric mixture, $(S, S)$ or $(R, S))$ in hydrogenated tetrapropylene (TPH). Extraction experiments were performed at two different concentrations of nitric acid $\left(4 \mathrm{~mol} \mathrm{~L}^{-1}\right.$ and $\left.0.5 \mathrm{~mol} \mathrm{~L}^{-1}\right)$ to evaluate the ability of the individual diastereoisomers of DEHBA to respectively co-extract $\mathrm{U}(\mathrm{VI})$ and $\mathrm{Pu}(\mathrm{IV})$ in the organic phase and then to separate $\mathrm{U}(\mathrm{VI})$ from $\mathrm{Pu}(\mathrm{IV})$ at lower nitric acid concentration. The performances of the extraction have been determined following the distribution ratio (D) and the U/Pu separation factor (SF) as illustrated in Figure 3.
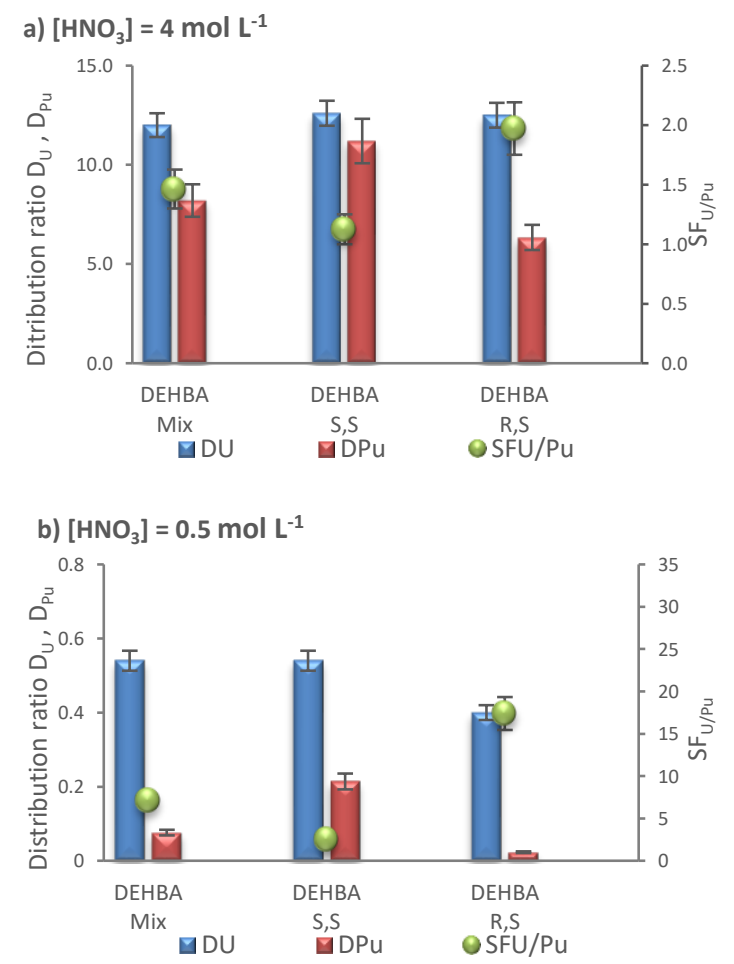

Figure 3 : Distribution ratios of uranium and plutonium, and $\mathrm{U} / \mathrm{Pu}$ separation factors for the $S, S$ and $R, S$ DEHBA stereoisomers compared with the stereoisomeric mixture for nitric acid concentration a) $\left[\mathrm{HNO}_{3}\right]_{\text {aq,ini }}=4 \mathrm{~mol} \mathrm{~L}^{-1}$ or b) $\left[\mathrm{HNO}_{3}\right]_{\mathrm{aq}, \mathrm{ini}}=0.5 \mathrm{~mol} \mathrm{~L}^{-1}$. Experimental conditions : $[\mathrm{U}(\mathrm{VI})]_{\mathrm{aq}, \text { ini }}=10 \mathrm{~g} \mathrm{~L}^{-1},[\mathrm{Pu}(\mathrm{IV})]_{\mathrm{aq}, \text { ini }}=0.2 \mathrm{~g} \mathrm{~L}^{-1} ;[\mathrm{DEHBA}]=1.2 \mathrm{~mol}$ $\mathrm{L}^{-1}$ in $\mathrm{TPH}, \mathrm{V}_{\mathrm{aq}}=\mathrm{V}_{\text {org }}, \mathrm{T}=25^{\circ} \mathrm{C}$.
The stereoisomeric mixture which was used as the reference molecule, exhibit metal ion distribution ratios $\left(D_{\cup}\right.$ and $\left.D_{P u}\right)$ close to those that can be found in the literature for this monoamide extractant. ${ }^{19}$ Uranium and plutonium are strongly extracted at high concentration of nitric acid with high distribution ratios (Figure 3a) which allows them to be co-extracted. At low concentration of nitric acid (Figure $3 \mathrm{~b}$ ), a separation factor of 7 between $U$ and $\mathrm{Pu}$ is reached.

The three systems have a comparable affinity for uranium which suggests that the stereochemistry has no influence on the extraction mechanism occurring during the extraction of uranium. A slight difference was observed at lower acidity for the $(R, S)$-DEHBA but this must be taken with caution given the low values obtained at $0.5 \mathrm{~mol} \mathrm{~L}^{-1}$.

For the extraction of plutonium, the behaviour is more strongly dependent on the stereochemistry of the extractant. Distribution ratios are different for $(S, S)$-DEHBA and $(S, R)$ DEHBA compared to the stereoisomeric mixture. At high concentration of nitric acid (Figure 3a), the distribution ratio of the $(S, S)$-DEHBA is significantly higher, approximately 1.3 times superior to the $\mathrm{D}_{\mathrm{Pu}}$ of the stereoisomeric mixture displaying an enhanced affinity with the metal. As a result the U/Pu separation factor gets close to 1 . While for $(R, S)$-DEHBA, a decrease in $D_{p u}$ is observed, which leads to an increase of the separation factor. The same behaviour is observed at lower acidity (Figure $3 b$ ), although an even greater difference was noticed between the distribution ratios of the different isomers. A factor 3 is observed between the $(S, S)$-DEHBA and the stereoisomeric mixture for the extraction of the element plutonium.

The results from this study have highlighted the nonnegligible impact of the stereochemistry on the extraction efficiency depending on the element extracted. No significant influence was noticed on the extraction of uranium while a substantial difference was observed for plutonium.

The difference in behaviour can be linked to the coordination structures of uranium and plutonium ions with DEHBA, particularly with the nitrate coordination number which differs between uranyl and plutonium cations. 20,21,22 Further studies and investigations are in progress in order to understand the mechanisms in motion during the extraction process and how the stereochemistry comes into place in the scheme of complexation and spatial arrangement as well as the influence of the stereochemistry on the supramolecular organization which was not considered in the literature. ${ }^{23}$

As mentioned, a large variety of extractant molecules used for the extraction of metals, contain the same molecular di-2-ethylhexyl pattern, which provides the chirality characteristic to the molecules. For the first time an optimized synthesis path for stereochemically-enriched di-2ethylhexylamine was proposed allowing enantiomeric excess superior to $90 \%$ and purity above $98 \%$. This molecule "platform" is a milestone for further studies to access various stereochemically pure extractants, as this fragment appears on a very wide range of extractant molecules. 


\section{Author Contributions}

Nicolas Felines: Investigation, Methodology, Visualization, Writing original draft. Guilhem Arrachart: Methodology, Supervision, Validation, Writing - review \& editing. Fabrice Giusti: Methodology. Audrey Beillard: Resources. Cécile Marie: Methodology, Resources. Stéphane Pellet-Rostaing: Methodology, Supervision, Validation, Project administration, Funding acquisition.

\section{Conflicts of interest}

"There are no conflicts to declare".

\section{Notes and references}

A. Chandrasekar, R. C. V. S. Brahmmananda, M. Sundararajan, T. K. Ghanty and N. Sivaraman, Dalt. Trans., 2018, 47, 3841-3850.

2 R. Turgis, A. Leydier, G. Arrachart, F. Burdet, S. Dourdain, G. Bernier, M. Miguirditchian and S. Pellet-Rostaing, Solvent Extr. Ion Exch., 2014, 32, 685-702. K. McCann, J. A. Drader and J. C. Braley, Sep. Purif. Rev., 2018, 47, 49-65. C. Berger, E. Moreau, C. Marie, D. Guillaumont, A. Beillard and L. Berthon, Solvent Extr. Ion Exch., 2021, 1-22. M. Lemaire, A. Guy, R. Chomel and J. Foos, J. Chem. Soc. Chem. Commun., 1991, 1152-1154. . Herlinger and B. P. Hay, Chem. Commun., 1999, 11771178. Y. Lin, J. Espinas, S. Pellet-Rostaing, A. Favre-Réguillon and M. Lemaire, New J. Chem., 2010, 34, 388-390. H. Tsukube, T. Yamada and S. Shinoda, Ind. Eng. Chem. Res., 2000, 39, 3412-3418. K. Ishimori, M. Watanabe, T. Kimura, T. Yaita, T. Yamada, Y Kataoka, S. Shinoda and H. Tsukube, Chem. Lett., 2005, 34, 1112-1113. A. Wilden, P. M. Kowalski, L. Klaß, B. Kraus, F. Kreft, G. Modolo, Y. Li, J. Rothe, K. Dardenne, A. Geist, A. Leoncini, J. Huskens and W. Verboom, Chem. - A Eur. J., 2019, 25, 5507-5513. A. Leoncini, J. Huskens and W. Verboom, Chem. Soc. Rev., 2017, 46, 7229-7273. C. Musikas, Inorganica Chim. Acta, 1987, 140, 197-206. G. M. Gasparini and G. Grossi, Solvent Extr. Ion Exch., 1986, 4, 1233-1271.

Ion Exch., 2014, 32, 348-364. R. B. Zerdan, N. T. Shewmon, Y. Zhu, J. P. Mudrick, K. J. Chesney, J. Xue and R. K. Castellano, Adv. Funct. Mater., 2014, 24, 5993-6004.

Soc., 1982, 104, 1737-1739. C. Larpent and X. Chasseray, Tetrahedron, 1992, 48, 39033914.

\footnotetext{
T. W. Baughman, J. C. Sworen and K. B. Wagener,
}

N. Condamines and C. Musikas, Solvent Extr. Ion Exch., 1992, 10, 69-100.

F. Rodrigues, G. Ferru, L. Berthon, N. Boubals, P. Guilbaud, C. Sorel, O. Diat, P. Bauduin, J. P. Simonin, J. P. Morel, N. Morel-Desrosiers and M. C. Charbonnel, Mol. Phys., 2014, 112, 1362-1374.

E. Acher, Y. Hacene Cherkaski, T. Dumas, C. Tamain, D. Guillaumont, N. Boubals, G. Javierre, C. Hennig, P. L. Solari and M.-C. Charbonnel, Inorg. Chem., 2016, 55, 5558-5569. E. Acher, T. Dumas, C. Tamain, N. Boubals, P. L. Solari and D. Guillaumont, Dalt. Trans., 2017, 46, 3812-3815. A. Paquet, O. Diat, L. Berthon and P. Guilbaud, J. Mol. Liq., 2019, 277, 22-35. Tetrahedron, 2004, 60, 10943-10948. 